Research Article

\title{
Isolation and Identification of Methicillin-Resistant Staphylococcus aureus (MRSA) from Milk in Shire Dairy Farms, Tigray, Ethiopia
}

\author{
Weldemelak Girmay, ${ }^{1}$ Getachew Gugsa ${ }^{1 D},{ }^{2}$ Habtamu Taddele, ${ }^{1}$ Yisehak Tsegaye, ${ }^{1}$ \\ Nesibu Awol, ${ }^{2}$ Meselu Ahmed, ${ }^{2}$ and Aklilu Feleke ${ }^{3}$ \\ ${ }^{1}$ College of Veterinary Sciences, Mekelle University, Mekelle, Ethiopia \\ ${ }^{2}$ School of Veterinary Medicine, Wollo University, Dessie, Ethiopia \\ ${ }^{3}$ Aklilu Lemma Institute of Pathobiology, Addis Ababa University, Addis Ababa, Ethiopia
}

Correspondence should be addressed to Getachew Gugsa; gugsag@yahoo.com

Received 5 May 2020; Revised 1 August 2020; Accepted 3 August 2020; Published 15 August 2020

Academic Editor: Francesca Mancianti

Copyright (C) 2020 Weldemelak Girmay et al. This is an open access article distributed under the Creative Commons Attribution License, which permits unrestricted use, distribution, and reproduction in any medium, provided the original work is properly cited.

\begin{abstract}
Antibiotic-resistant Staphylococcus aureus isolates pose a severe challenge to both veterinary and health professions and dairy cattle producers. Cross-sectional study was conducted from November 2014 to May 2015 to isolate and identify S. aureus from mastitic cows' milk and estimate the occurrence of MRSA in the dairy farms of Shire. Physical examination and California mastitis test were performed on a total of 220 dairy cows. Bacteriological isolation and identification and antibiogram testing were performed. Furthermore, multiplex polymerase chain reaction (PCR) was done for the detection of mec $A$ and fem $A$ genes. Out of the 220 dairy cows, 64 (29.09\%) were positive for bovine mastitis, and of these, $32.81 \%$ were coagulase-positive S. aureus (CoPS). Antibiogram test results showed $100 \%$ of the isolates were resistant to penicillin G, nalidixic acid, and ampicillin, and $33.33 \%$ of the CoPS showed resistance to oxacillin (phenotypically MRSA positive). But 38.09\% of the CoPS were found to be resistant and susceptible to vancomycin. PCR amplification of the seven phenotypically MRSA isolates revealed that $42.9 \%$ and $71.4 \%$ of them were found to carry fem $A$ and mec $A$ genes, respectively. The current study revealed the existence of alarming level of CoPS and development of multidrug resistance.
\end{abstract}

\section{Introduction}

Roughly $75 \%$ of the infectious diseases in humans over the past two decades have originated from animals and can transmit directly or indirectly from animals to humans [1]. Staphylococcus aureus (S. aureus) is recognized worldwide as a leading pathogen causing many serious diseases in dairy and healthcare surroundings [2]. In the last few decades, Staphylococcal food poisoning has been reported as the third cause of food-borne illnesses in the world [3]. Moreover, antibiotic-resistant $S$. aureus isolates pose a severe challenge to both veterinary and health professions and dairy cattle producers because they have a negative impact on therapy [4]. In the 1960 s, approximately $80 \%$ of all clinical isolates of
S. aureus were $\beta$-lactamase producers [5]. In the early 1960s, the first isolates of MRSA were detected in the United Kingdom (UK) [6].

The antibiotic resistance mechanism of MRSA is mediated through expression of mec $A$, encoding a penicillinbinding protein $\mathrm{PBP} 2 \mathrm{a}$ that has a low affinity for $\beta$-lactam antibiotics [7]. The mec $A$ gene is a DNA segment of $2.1 \mathrm{~kb}$ that is non-native to $S$. aureus and is inserted in a large block of exogenous DNA, known as the staphylococcal cassette chromosome mec (SCCmec) [8].

Infections due to MRSA have increased worldwide during the past twenty years [9]. Traditionally, two groups are distinguished among its strains: hospital-acquired MRSA (HA-MRSA) and community-acquired MRSA (CA-MRSA) 
[10]. However, MRSA infection and colonization have also been reported in horses, dogs, cats, birds, dairy cows, and chicken, and this new type of isolate emerged into the S. aureus population, belonging to clonal complex 398 (CC398) and is known as livestock-associated MRSA (LAMRSA) [11, 12]. Hence, besides its importance as a hospital and community pathogen, MRSA has also been considered as an emerging problem in veterinary medicine in recent years $[13,14]$.

In recent years, MRSA strains have been recovered from several animal-source foods, such as poultry, pork, and beef, suggesting that foods may serve as the reservoir and source of CA-MRSA [15]. Milk has been reported to be contaminated with MRSA, which is suspected to have been acquired from dairy animals or from postmilking contamination and poor sanitary practice [16]. In addition, S. aureus is considered as one of the most important causative agents of mastitis in dairy cattle [17]. Hence, determination of antimicrobial resistance profile of LA-MRSA isolates is crucial for empirical treatment of infections associated with LAMRSA. Moreover, there was no published and/or accessible research work in the current study area, Shire, as well as in the region. Thus, the objective of this study was to isolate and identify $S$. aureus from mastitic cows' milk and estimate the occurrence of MRSA.

\section{Materials and Methods}

2.1. Study Area. The study was conducted from November 2014 to May 2015 in Shire, Ethiopia. Shire is located at about $1087 \mathrm{~km}$ north of Addis Ababa and $304 \mathrm{~km}$ from Mekelle at an altitude of 1984 meter above sea level. It is located between $14^{\circ} 6^{\prime} \mathrm{N} 38^{\circ} 17^{\prime} \mathrm{E} / 14.100^{\circ} \mathrm{N} 38.283^{\circ} \mathrm{E}$ latitude and longitude, respectively. The average range of temperature is $25^{\circ} \mathrm{C}-35^{\circ} \mathrm{C}$, with $900-1100 \mathrm{~mm}$ of annual average range of rainfall. There are four milk shades (dairy farms) containing about 1500 dairy cattle kept in these farms (shades), of which 579 were crossbred dairy cows and the remaining were calves and heifers [18].

2.2. Study Design. A cross-sectional type of study was conducted from November 2014 to May 2015 in the Shire town, Northwest of Tigray, Ethiopia, to isolate and identify $S$. aureus from mastitic cows' milk and estimate the occurrence of MRSA strains.

2.3. Sample Size and Sample Collection. A total of 220 dairy cows from the four milk shades were selected purposively on the bases of the availability of dairy cows and the willingness and cooperation of the farm owners during sampling. About $10 \mathrm{~mL}$ of the milk sample was aseptically collected from each of clinically and subclinically (CMT positive) mastitis nonblind quarters of the selected cows using sterile universal bottles for bacterial isolation according to the study by Quinn et al. [19]. Then, the collected samples were transported in an ice box to the Mekelle University, College of Veterinary Sciences, Microbiology Laboratory for microbiological examination. If immediate inoculation was not convenient, the samples were kept at $4^{\circ} \mathrm{C}$ for a maximum of $24 \mathrm{~h}$ until cultured on standard bacteriological media.

2.4. Bacteriological Isolation and Identification. A loop of milk sample was streaked on 5\% Sheep Blood Agar (Oxoid, $\mathrm{UK})$, and the plates were incubated aerobically at $37^{\circ} \mathrm{C}$ and examined after $24 \mathrm{~h}$ of incubation for growth. The colonies were provisionally identified on the basis of staining reaction with Gram's stain, cellular morphology, and hemolytic pattern on blood agar. The representative colonies were subcultured on Mannitol Salt Agar (MSA) (Oxoid, UK) and incubated at $37^{\circ} \mathrm{C}$. Then, the colonies that grew on MSA were subcultured on nutrient media, and the cultures were preserved and maintained for characterizing the isolates. Catalase test, oxidase test, tube coagulase test, DNase test, and growth on MSA were performed according to the study by Quinn et al. [19], and samples that were considered as positive for coagulase-positive $S$. aureus (CoPS) were further characterized.

2.5. Antimicrobial Susceptibility Testing. The S. aureus isolates were screened for in vitro antimicrobial susceptibility using the agar disk diffusion method according to the procedure given by Kirby et al. [20] on Mueller-Hinton agar (Oxoid Ltd., Basingstoke, Hampshire, England). It is stated that in the absence of methicillin, the best alternative is to use cefoxitin or oxacillin for MRSA identification [21]. The following eleven different antibiotic discs, with their concentrations given in parentheses, were used in the antibiogram testing: oxacillin $(1 \mu \mathrm{g})$ (Abtek Biologicals Ltd, Liverpool, UK), vancomycin $(30 \mu \mathrm{g})$, penicillin $\mathrm{G}(10 \mu \mathrm{g})$, oxytetracycline $(30 \mu \mathrm{g})$, streptomycin $(25 \mu \mathrm{g})$, trimethoprim $(5 \mu \mathrm{g})$, amoxicillin/clavulanic acid (30 $\mu \mathrm{g})$, ampicillin $(10 \mu \mathrm{g})$, nalidixic acid $(30 \mu \mathrm{g})$, compound sulfonamides $(300 \mu \mathrm{g})$, and kanamycin $(30 \mu \mathrm{g})$ (Oxoid Company, Hampshire, England). After $24 \mathrm{~h}$ of incubation, the clear zones (inhibition zones) of bacterial growth around the antibiotic disc (including the discs) diameter for individual antimicrobial agents were measured and then translated into sensitive (S), intermediate (I), and resistant (R) categories according to the interpretation table of the Clinical and Laboratory Standard Institute [22].

2.6. Polymerase Chain Reaction (PCR) for Detection of mec $A$ and fem $A$ Genes. The $S$. aureus genomic DNA extraction and purification were performed as per the protocol given by Thermo Scientific, GeneJET Genomic DNA Purification Kit for gram-positive organisms. Then, seven of the phenotypically MRSA isolates were screened for the presence of $m e c A$ and $f e m A$ genes by multiplex PCR according to the procedure given by Johnson et al. [23] using the following specific primers: F-5'GTA GAA ATG ACT GAA CGT CCG ATA A3' and R-5'CCA ATT CCA CAT TGT TTC GGT CTA $A 3^{\prime}$ for mec A gene (having a band size of $310 \mathrm{bp}$ ) and F-5'-AAA AAA GCA CAT AAC AAG CG- $3^{\prime}$ and R-5'GAT AAA GAA GAA ACG AGC AG-3' for fem A gene ( $S$. aureus species specific and encoding a factor responsible for 
methicillin resistance and has an amplicon size of $132 \mathrm{bp}$ ). Each PCR reaction mixture $(50 \mu \mathrm{L})$ was prepared from $5 \mu \mathrm{L}$ of $10 \mathrm{X}$ reaction buffer, $5 \mu \mathrm{L}$ of template DNA, $1 \mu \mathrm{L}$ of each primer, $3 \mu \mathrm{L}$ of $10 \mathrm{mM}$ dNTP mixture, and $1 \mu \mathrm{L}$ of Taq polymerase. The remaining volume had nuclease-free deionized water. Amplification was carried out in a Tianlong PCR thermocycler with thermal cycling conditions of an initial denaturation at $94^{\circ} \mathrm{C}$ for 6 min followed by 35 cycles of denaturation at $94^{\circ} \mathrm{C}$ for $45 \mathrm{~s}$, annealing at $55^{\circ} \mathrm{C}$ for $30 \mathrm{~s}$ and extension at $72^{\circ} \mathrm{C}$ for $45 \mathrm{~s}$, and with final extension at $72^{\circ} \mathrm{C}$ for $6 \mathrm{~min}$. Finally, PCR products were separated by running on $1.5 \%(\mathrm{w} / \mathrm{v})$ agarose gel containing $0.5 \mathrm{~g} / \mathrm{mL}$ ethidium bromide. Electrophoresis was conducted in a horizontal equipment system for $55 \mathrm{~min}$ at $110 \mathrm{~V}$ using $1 \mathrm{X}$ TAE buffer (40 mM Tris, $1 \mathrm{mM}$ EDTA and $20 \mathrm{mM}$ glacial acetic acid, $\mathrm{pH}$ 8.0). The amplicons were visualized under UV-light gel doc, and their molecular weights were estimated by comparing with 100 bp DNA molecular weight marker (Solis BioDyne, Tartu, Estonia) [24].

2.7. Data Management and Analysis. All collected data were entered into Microsoft Excel Sheet and analyzed through Statistical Package for Social Sciences, version 16. Accordingly, descriptive statistics such as percentages and frequency distribution were used to determine the prevalence.

\section{Results}

The physical examination of the udder and CMT test results indicated that out of the 220 dairy cows, 64 (29.09\%) were positive for bovine mastitis. Bacteriological characterization of these 64 mastitis-positive samples revealed that 21 (32.81\%) were found CoPS. The antimicrobial sensitivity test results of the 21 CoPS isolates showed their susceptibility to kanamycin and streptomycin (42.85\%). However, $100 \%$ of the isolates were resistant to penicillin G, nalidixic acid, and ampicillin, $85.71 \%$ to amoxicillin, $47.61 \%$ to trimethoprim and oxytetracycline, and $57.14 \%$ to compound sulfonamides, and $33.33 \%$ of the CoPS were resistant for oxacillin (phenotypically MRSA positive). But $38.09 \%$ of the CoPS were found to be resistant and susceptible to vancomycin. Moreover, all the $21(100 \%)$ isolates developed multidrug resistance as it is shown in Table 1.

The PCR amplification of the seven phenotypically MRSA isolates was revealed that $3(42.9 \%)$ of them were found to carry fem $A$ gene and 5 (71.4\%) of them were found to carry mec $A$ genes, which had a molecular weight of $132 \mathrm{bp}$ and $310 \mathrm{bp}$, respectively.

\section{Discussion}

The overall prevalence of bovine mastitis in the study dairy farms was $29.09 \%$. This finding was more or less in line with the reports of Molalegne et al. [25] in Bahir Dar and its environs, Ethiopia (28.8\%), Mulugeta and Wassie [26] in and around Wolaita Sodo, Ethiopia (29.5\%), and Bekele et al. [27] in Hawassa Town, Ethiopia (34.3\%). However, it was lower than the reports of Indu and Brintya [28] in Silchar Town Dairy Farms, North East India (35.83\%), Rgbe et al.
[29] in Northern Ethiopia (37.4\%), Biniam et al. [30] in and around Wolaita Sodo, Southern Ethiopia (40.9\%), Pati and Reena [31] from Northern Plains of India (42.76\%), Anueyiagu and Isiyaku [32] in Plateau State, Nigeria (43.75\%), Abera et al. [33] in Adama Town, Ethiopia (46.7\%), Asmelash et al. [34] in and around Kombolcha, Ethiopia (56\%), Tilahun et al. [35] in and around Kombolcha Town, Eastern Amhara, Ethiopia (56\%), and Shimels et al. [36] in the Selale/Fitche area, North Showa, Ethiopia (83.1\%). The differences in the prevalence of bovine mastitis might be due to the fact that mastitis is a complex disease and associated with different risk factors such as husbandry and management systems of the farms, difference in drug usages and/or treatment, and the geographical locations of the study sites.

The current study revealed $32.81 \%$ prevalence of CoPS. This finding was nearly comparable with the findings of Zeryehun et al. [37] in and around Addis Ababa, Ethiopia (28.8\%), Joshi et al. [38] in Pokhara, Nepal (29.7\%), Suleiman et al. [39] in Plateau State, Nigeria (30.9\%), Fitsum [40] in Wolayta Sodo, Ethiopia (32.14\%), Muyiwa et al. [41] in Mafikeng town, North-West Province of South Africa (32.5\%), Pati and Reena [31] from Northern Plains of India (32.8\%), Birhanu et al. [42] in Asella, South Eastern Ethiopia (35.71\%), Rgbe et al. [29] in Northern Ethiopia (36\%), and Biniam et al. [30] in and around Wolaita Sodo, Southern Ethiopia (37.14\%). However, the present finding result was higher than that reported by Riva et al. [43] (9.1\%), Gali et al. [44] in Zaria and Kaduna, Nigeria (12.6\%), Gali et al. [45] in Nigeria (12.63\%), Basanisi et al. [46] in South Italy (12.9\%), Abebe et al. [47] around Addis Ababa, Ethiopia (16.2\%), Kapllan et al. [48] in Fieri Region in Albania (18\%), Fufa et al. [49] in and around Asella, Ethiopia (19.3\%), Asiimwe et al. [50] in South-West Uganda (20.3\%), Molalegne et al. [25] in Bahir Dar town and its environs, Ethiopia (20.3\%), Takele et al. [51] in Addis Ababa, Ethiopia (20.8\%), Yodit et al. [52] in Sebeta, Central Oromia, Ethiopia (23.4\%), and Mueena et al. [53] in Bangladesh (25.53\%); but it was lower than that reported by Sudhanthirakodi et al. [54] in the region of Tirupathi, India (39.09\%), Abera et al. [33] in Adama town, Ethiopia (42.14\%), Fanta et al. [55] in urban and peri-urban areas of Debre-Zeit, Ethiopia (44\%), Ananya and Pranab [56] in Southern Assam, India (47.86\%), Deresse et al. [57] in Hawassa area, Ethiopia (48.75\%), Jolanta et al. [58] in Poland (50.0\%), Shimels et al. [36] in the Selale/Fitche area, North Showa, Ethiopia (51.56\%), Gali et al. [44] in Zaria and Kaduna, Nigeria (52.42\%), Bekele et al. [27] in Hawassa town, Ethiopia (53.5\%), Pant et al. [59] from different regions of Dehradun (60\%), Jibril and Huruma [60] in the Morogoro Municipality, Tanzania (64.10\%), Purba et al. [61] in Karnal, North India (74.5\%), and Indu and Brintya [28] in Silchar Town, North East India (83.72\%). These differences in the prevalence of $S$. aureus from the different studies might be due to variations in sample size, isolation techniques, husbandry practices, awareness and skills of the farm owners, animal health delivery systems, and geographic regions of the sampled area.

The antimicrobial sensitivity test results of the current CoPS isolates was almost in agreement with the findings of 
TABLE 1: In vitro antimicrobial drug susceptibility test results of $S$. aureus isolates.

\begin{tabular}{lccc}
\hline Antimicrobial discs & & Interpretations & \\
& Susceptible no. (\%) & Intermediate no. (\%) & Resistant no. (\%) \\
\hline Ampicillin & 0 & 0 & $21(100)$ \\
Nalidixic acid & 0 & 0 & $21(100)$ \\
Kanamycin & $9(42.85)$ & $5(23.8)$ & $7(33.33)$ \\
Trimethoprim & $8(38.09)$ & $3(14.28)$ & $10(47.61)$ \\
Streptomycin & $9(42.85)$ & $4(19.04)$ & $8(38.09)$ \\
Oxytetracycline & $9(42.85)$ & $1(4.76)$ & $10(47.61)$ \\
Amoxicillin & $3(14.285)$ & 0 & $18(85.71)$ \\
Oxacillin & $12(57.14)$ & $2(9.52)$ & $7(33.33)$ \\
Penicillin G & 0 & 0 & $21(100)$ \\
Vancomycin & $8(38.09)$ & $4(19.04)$ & $8(38.09)$ \\
Compound sulfonamides & $1(4.76)$ & $8(38.09)$ & $12(57.14)$ \\
\hline
\end{tabular}

Asmelash et al. [34] who reported $100 \%$ resistant to penicillin $\mathrm{G}$ and amoxicillin and $42.7 \%$ to cefoxitin; Abera et al. [33] who reported $94.4 \%$ resistant to penicillin $\mathrm{G}$ and $58.3 \%$ to trimethoprim-sulfamethoxazole; Rgbe et al. [29] who reported $82.4 \%$ of resistant to ampicillin and $52.9 \%$ to trimethoprim-sulfamethoxazole; Abebe et al. [47] who observed $92.2 \%$ resistant to penicillin $G$ and $33.3 \%$ to oxacillin; Abo-Shama [62] in Sohag Governorate, Egypt, who reported $43.1 \%$ resistant to oxacillin and $83.7 \%$ to one or more antimicrobial agent; Mueena et al. [53] who reported $100 \%$ resistant to penicillin and amoxicillin; Fitsum [40] who reported $93.3 \%$ resistant to penicillin G, $53.3 \%$ to streptomycin, and $40 \%$ to tetracycline; Tilahun et al. [35] who observed $100 \%$ resistant to penicillin $G$ and amoxicillin and $42.7 \%$ to cefoxitin; Muyiwa et al. [41] who illustrated a large proportion $(60 \%-100 \%)$ of resistant to penicillin G, ampicillin, and streptomycin; Ananya and Pranab [56] who reported $87.5 \%$ resistant to penicillin G; Pati and Reena [31] who reported $96 \%$ resistant to penicillin G and 93\% to ampicillin; and Jibril and Huruma [60] who reported $71.74 \%$ of resistant to penicillin $\mathrm{G}$ and $41.30 \%$ to tetracycline.

Moreover, the current result was in line with that of Indu and Brintya [28] who observed $76.78 \%$ resistant to penicillin $G$ and $91.07 \%$ to nalidixic acid; Biniam et al. [30] who observed $100 \%$ resistant to penicillin G, $61.5 \%$ to amoxicillin-clavulanic acid, $66.7 \%$ to streptomycin, and $71.8 \%$ multidrug resistance; Suleiman et al. [39] who reported $35.6 \%$ resistant to oxacillin; Fufa et al. [49] who reported $95.5 \%$ resistant to penicillin G; Shimels et al. [36] who reported $36.6 \%$ MRSA; Sudhanthirakodi et al. [54] who reported $86.04 \%$ resistant to penicillin G and $74.42 \%$ to ampicillin; Gali et al. [44] who reported $100 \%$ of resistant to penicillin $\mathrm{G}$ and $46.8 \%$ to oxacillin, $55.6 \%$ to tetracycline, $44.6 \%$ to vancomycin, detected mec $A$ by polymerase chain reaction in 4 of the 18 MRSA isolates, and $88.9 \%$ multidrug resistance; Gali et al. [45] who reported $100 \%$ of resistant to penicillin G, 65\% to amoxicillin, and $40 \%$ to oxacillin; Yodit et al. [52] who reported $98.5 \%$ of resistant to penicillin G; Takele et al. [51] who reported $95.3 \%$ of resistant to penicillin G, $88.4 \%$ to nalidixic acid, and $100 \%$ multidrug resistance; and Fufa et al. [49] who reported $95.5 \%$ of resistant to penicillin $\mathrm{G}$ and $95.5 \%$ multidrug resistance. However, the current finding of MRSA was higher than that reported by
Ananya and Pranab [56] (8.93\%), Sudhanthirakodi et al. [54] (13.95\%), Basanisi et al. [46] (8.3\%), Gali et al. [44] (4.8\%), and Jibril and Huruma [60] (6.52\%). The detection of mec $A$ by the PCR is considered a gold-standard technique for oxacillin resistance detection [63]. The resistance of $S$. aureus to penicillin and closely related antibiotics might be attributed to the production of $\beta$-lactamase, an enzyme that inactivates penicillin and closely related antibiotics. Around $50 \%$ of mastitis-causing $S$. aureus strains produce $\beta$-lactamase [64]. Moreover, the development of antimicrobial resistance might be as a result of repeated therapeutic and/or indiscriminate use of them in the dairy farms, particularly penicillin and oxytetracycline for the treatment of mastitis cases in the study area at large in the country.

\section{Conclusion and Recommendations}

The current study revealed that there is a high prevalence of CoPS as well as MRSA as a cause of bovine mastitis. Though nearly half of the CoPS isolates were susceptible to kanamycin and streptomycin, the high percentage were resistant to penicillin $G$, nalidixic acid, ampicillin, amoxicillin, trimethoprim, oxytetracycline, compound sulfonamides, oxacillin, and vancomycin. Moreover, all of the CoPS isolates developed multidrug resistance. This higher percentage of multidrug resistance pattern indicates alarming situation for designing prevention and control measures. However, the current study was only targeting mec $A$ and fem $A$ genes for a few of the phenotypically MRSA-positive isolates for molecular characterization. In general, the detection of CoPS in the milk samples and development of drug resistance indicate that the product is unwholesome for human consumption. Hence, it has a serious economic, animal welfare, food safety, and public health problem. Therefore, strict hygiene should be implemented in the farms by creating awareness among the farm workers, managers, and attendants regarding transmission, zoonotic importance, and control and prevention strategies of the disease; and dispensing of non-prescribed drugs and indiscriminate use of antibiotics should be avoided. Moreover, further studies on molecular characterization and sequencing of MRSA should be conducted by targeting other important genes in addition to the targeted genes in the study area at large in the country. 


\section{Data Availability}

The data used to support the findings of this study are available from the corresponding author upon request.

\section{Conflicts of Interest}

The authors state that there are no conflicts of interest.

\section{Acknowledgments}

The authors acknowledge the College of Veterinary Sciences, Mekelle University for the financial support. The authors would like to extend their acknowledgement to the different dairy farm owners, farm managers, and farm workers of the study site for their keen interest and cooperation during collection of the milk samples and to the College of Veterinary Sciences staff members who were directly or indirectly helped us during the research period.

\section{References}

[1] European Food Safety Authority (EFSA), "Scientific report of EFSA: technical specifications on the harmonized monitoring and reporting of antimicrobial resistance in methicillin-resistant Staphylococcus aureus in food-producing animals and food," EFSA Journal, vol. 10, p. 2897, 2012.

[2] P. L. Graham, S. X. Lin, and E. L. Larson, "A U.S. Populationbased survey of Staphylococcus aureus colonization," Annals of Internal Medicine, vol. 144, no. 5, pp. 318-325, 2006.

[3] C. Ateba, M. Mbewe, M. S. Moneoang, and C. C. Bezuidenhout, "Antibiotic-resistant Staphylococcus aureus isolated from milk in the Mafikeng area, north west province, South Africa," South African Journal of Science, vol. 106, pp. 12-13, 2010.

[4] E. Brouillette and F. Malouin, "The pathogenesis and control of Staphylococcus aureus-induced mastitis: study models in the mouse," Microbes and Infection, vol. 7, no. 3, pp. 560-568, 2005.

[5] O. Jessen, K. Rosendal, P. Bülow, V. Faber, and K. R. Eriksen, "Changing staphylococci and staphylococcal infections," New England Journal of Medicine, vol. 281, no. 12, pp. 627-635, 1969.

[6] J. M. Boyce, "Increasing prevalence of methicillin-resistant Staphylococcus aureus in the United States," Infection Control and Hospital Epidemiology, vol. 11, no. 12, pp. 639-642, 1990.

[7] K. Hiramatsu, L. Cui, M. Kuroda, and T. Ito, "The emergence and evolution of methicillin-resistant Staphylococcus aureus," Trends in Microbiology, vol. 9, no. 10, pp. 486-493, 2001.

[8] Y. Katayama, T. Ito, and K. Hiramatsu, "A new class of genetic element, Staphylococcus cassette chromosome mec, encodes methicillin resistance in Staphylococcus aureus," Antimicrobial Agents and Chemotherapy, vol. 44, no. 6, pp. 1549-1555, 2000.

[9] G. Ippolito, S. Leone, F. N. Lauria, E. Nicastri, and R. P. Wenzel, "Methicillin-resistant Staphylococcus aureus: the superbug," International Journal of Infectious Diseases, vol. 14, no. 4, pp. S7-S11, 2010.

[10] C. Cuny, R. Köck, and W. Witte, "Livestock associated MRSA (LA-MRSA) and its relevance for humans in Germany," International Journal of Medical Microbiology, vol. 303, no. 67, pp. 331-337, 2013.
[11] J. S. Weese, "Methicillin-ResistantStaphylococcus aureus: an emerging pathogen in small animals," Journal of the American Animal Hospital Association, vol. 41, no. 3, pp. 150-157, 2005.

[12] M. E. Stryjewski and G. R. Corey, "Methicillin-resistant Staphylococcus aureus: an evolving pathogen," Clinical Infectious Diseases, vol. 58, no. 1, pp. S10-S19, 2014.

[13] M. Spohr, J. Rau, A. Friedrich et al., "Methicillin-resistant Staphylococcus aureus (MRSA) in three dairy herds in Southwest Germany," Zoonoses and Public Health, vol. 58, no. 4, pp. 252-261, 2011.

[14] B. Walther, L. H. Wieler, A. W. Friedrich et al., "Methicillinresistant Staphylococcus aureus (MRSA) isolated from small and exotic animals at a university hospital during routine microbiological examinations," Veterinary Microbiology, vol. 127, no. 1-2, pp. 171-178, 2008.

[15] X. Wang, G. Li, X. Xia, B. Yang, M. Xi, and J. Meng, “Antimicrobial susceptibility and molecular typing of methicillinresistant Staphylococcus aureus in retail foods in shaanxi, China," Foodborne Pathogens and Disease, vol. 11, no. 4, pp. 281-286, 2014.

[16] J. E. Virgin, T. M. van Slyke, J. E. Lombard, and R. N. Zadoks, "Short communication: methicillin-resistant Staphylococcus aureus detection in US bulk tank milk," Journal of Dairy Science, vol. 92, no. 10, pp. 4988-4991, 2009.

[17] H.-M. Nam, A.-L. Lee, S.-C. Jung et al., “Antimicrobial susceptibility ofStaphylococcus aureusand characterization of methicillin-ResistantStaphylococcus aureusIsolated from bovine mastitis in korea," Foodborne Pathogens and Disease, vol. 8, no. 2, pp. 231-238, 2011.

[18] BoANR, "Livestock census analysis result," Report, Bureau of Agriculture and Natural Resources, Adigrat, Tigray, Ethiopia, 2010.

[19] P. J. Quinn, E. Carter, B. Markey, and R. Carter, "Mastitis," in Clinical Veterinary Microbiology, pp. 327-344, Mosby International Limited, London, UK, 1999.

[20] W. M. Kirby, A. W. Baue, J. C. Sherris, and M. Turck, "Antibiotic susceptibility testing by a standard single disc method," American Journal of Clinical Pathology, vol. 45, pp. 493-496, 1966.

[21] National Committee for Clinical Laboratory Standards (NCCLS), Performance Standards for Antimicrobial Susceptibility Testing, 7th Informational Supplement, Approved Standard, pp. M100-S21, National Committee for Clinical Laboratory Standards, Wayne, PA, USA, 2012.

[22] Clinical and Laboratory Standards Institute (CLSI), Performance Standards for Antimicrobial Susceptibility Testing; Twenty-Fourth Informational Supplement, CLSI, Wayne, PA, USA, 2014.

[23] W. M. Johnson, S. D. Tyler, E. P. Ewan, F. E. Ashton, D. R. Pollard, and K. R. Rozee, "Detection of genes for enterotoxins, exfoliative toxins, and toxic shock syndrome toxin 1 in Staphylococcus aureus by the polymerase chain reaction," Journal of Clinical Microbiology, vol. 29, no. 3, pp. 426-430, 1991.

[24] E. Pérez-Roth, F. Claverie-Martín, N. Batista, A. Moreno, and S. Méndez-Álvarez, "Mupirocin resistance in methicillin-resistant Staphylococcus aureus clinical isolates in a Spanish hospital. Co-application of multiplex PCR assay and conventional microbiology methods," Diagnostic Microbiology and Infectious Disease, vol. 43, no. 2, pp. 123-128, 2002.

[25] B. Molalegne, T. Arega, and T. Tadele, "Study on bovine mastitis in dairy farms of Bahir Dar and its Environs," Journal of Animal and Veterinary Advances, vol. 9, no. 23, pp. 2912-2917, 2010. 
[26] Y. Mulugeta and M. Wassie, "Prevalence, risk factors and major bacterial causes of bovine mastitis in and around Wolaita Sodo, Southern Ethiopia," African Journal of Microbiology Research, vol. 7, no. 48, pp. 5400-5405, 2013.

[27] M. Bekele, M. Admasu, A. Mesele, R. Alemayehu, and A. Fufa, "Mastitis in lactating cows at Hawassa town: prevalence, risk factors, major bacterial causes and treatment response to routinely used antibiotics," AEJSR, vol. 7, no. 2, pp. 86-91, 2012.

[28] S. Indu and A. Brintya, "Isolation and identification of Staphylococcus aureus from bovine mastitis milk and their drug resistance patterns in Silchar town dairy farms, N.E India," Online International Interdisciplinary Research Journal, vol. 4, pp. 256-260, 2014.

[29] H. Rgbe, T. Habtamu, G. Getachew, and K. Shewit, "Prevalence, bacterial causes, and anti-microbial susceptibility profile of mastitis isolates from cows in large scale dairy farms in Northen Ethiopia," Tropical Animal Health and Production, vol. 44, no. 7, pp. 1765-1771, 2012.

[30] T. D. Biniam, T. B. Biruk, S. T. Tesfaye, and K. W. Ashenafi, "Isolation and identification of methicilin resistant Staphylcoccus aureus (MRSA) from bovine mastitic milk in and around Wolaita Sodo, Southern Ethiopia," Open Access Journal of Veterinary Science \& Research OAJVSR, vol. 2, no. 3, Article ID 000136, 2017.

[31] B. K. Pati and M. Reena, "Characterization of Staphylococcus aureus isolates of bovine mastitis origin and antibiotic sensitivity pattern from Northern Plains of India," Journal of Veterinary Science and Animal Husbandry, vol. 1, no. 1, p. 105, 2016.

[32] K. N. Anueyiagu and A. W. Isiyaku, "Isolation, identification of Staphylococcus aureus from bovine milk and its antibiotics susceptibility," International Journal of Livestock Production, vol. 6, no. 6, pp. 74-77, 2015.

[33] M. Abera, B. Demie, K. Aragaw, F. Regassa, and A. Regassa, "Isolation and identification of Staphylococcus aureus from bovine mastitic milk and their drug resistance patterns in Adama town, Ethiopia," Journal of Veterinary Medicine and Animal Health, vol. 2, no. 3, pp. 29-34, 2010.

[34] T. Asmelash, N. Mesfin, D. Addisu, F. Aklilu, T. Biruk, and S. Tesfaye, "Isolation, identification and drug resistance patterns of methicillin resistant Staphylococcus aureus from mastitic cows milk from selected dairy farms in and around Kombolcha, Ethiopia," Journal of Veterinary Medicine and Animal Health, vol. 8, no. 1, pp. 1-10, 2016.

[35] K. A. Tilahun, Y. A. Mamo, and R. A. Mulatu, "Isolation and identification of methicillin resistant $S$. aureus (MRSA) from mastitic cow's milk," International Journal of Veterinary Science, vol. 1, no. 3, pp. 014-023, 2016.

[36] T. Shimels, T. Bruk, and S. Tesfaye, "Isolation and antimicrobial susceptibility of Staphylococcus aureus and occurrence of methicillin resistant Staphylococcus aureus (MRSA) in mastitic dairy cows in the Selale/Fitche Area, North Showa, Ethiopia," pp. 1-80, Addis Ababa University, Addis Ababa, Ethiopia, 2014, MSc thesis.

[37] T. Zeryehun, T. Aya, and R. Bayecha, "Study on prevalence, bacterial pathogens and associated risk factors of bovine mastitis in small holder dairy farms in and around Addis Ababa, Ethiopia," Journal of Animal and Plant Sciences, vol. 23, no. 1, pp. 50-55, 2013.

[38] L. R. Joshi, A. Tiwari, S. P. Devkota, S. Khatiwada, S. Paudyal, and K. R. Pande, "Prevalence of methicillin-resistant Staphylococcus aureus (MRSA) in dairy farms of Pokhara, Nepal,"
International Journal of Veterinary Science, vol. 3, no. 2, pp. 87-90, 2014.

[39] A. B. Suleiman, V. J. Umoh, J. K. P. Kwaga, and S. J. Shaibu, "Prevalence and antibiotic resistance profiles of methicillin resistant Staphylococcus aureus (MRSA) isolated from bovine mastitic milk in Plateau State, Nigeria," IRJM, vol. 2, no. 8, pp. 264-270, 2012.

[40] T. Fitsum, "Prevalence and drug resistance patterns of Staphylococcus aureus in lactating dairy cow's milk in Wolayta Sodo, Ethiopia," ECVE, vol. 2, pp. 226-230, 2016.

[41] A. A. Muyiwa, O. B. Olubukola, and N. A. Collins, "Detection of antibiotic resistant Staphylococcus aureus from milk: a public health implication," International Journal of Environmental Research and Public Health, vol. 12, pp. 1025410275, 2015.

[42] A. Birhanu, L. Diriba, and I. Iyob, "Study of bovine mastitis in Asella government dairy farm of Oromia regional state, South Eastern Ethiopia," IJCRAR, vol. 1, no. 2, pp. 134-145, 2013.

[43] A. Riva, E. Borghi, D. Cirasola et al., "Methicillin-resistant Staphylococcus aureus in raw milk: prevalence, SCCmec typing, enterotoxin characterization, and antimicrobial resistance patterns," Journal of Food Protection, vol. 78, no. 6, pp. 1142-1146, 2015.

[44] A. U. Gali, K. Junaid, V. Ju, B. Mohammed, and K. P. K. Jacob, "Methicillin-resistant Staphylococcus aureus (MRSA) in fresh and fermented milk in Zaria and Kaduna, Nigeria," IJDRT, vol. 3, no. 3, pp. 67-75, 2013.

[45] A. U. Gali, K. Junaid, V. Ju, B. Mohammed, and K. P. K. Jacob, "Occurrence of vancomycin-resistant Staphylococcus aureus (VRSA) in fresh and fermented milk in Nigeria: a preliminary report," IJPHER, vol. 3, no. 8, pp. 054-058, 2014.

[46] M. G. Basanisi, G. La Bella, G. Nobili, I. Franconieri, and G. La Salandra, "Genotyping of methicillin-resistant Staphylococcus aureus (MRSA) isolated from milk and dairy products in South Italy," Food Microbiology, vol. 62, pp. 141-146, 2017.

[47] M. Abebe, A. Daniel, W. Yimtubezinash, and T. Genene, "Identification and antimicrobial susceptibility of Staphylococcus aureus isolated from milk samples of dairy cows and nasal swabs of farm workers in selected dairy farms around Addis Ababa, Ethiopia," African Journal of Microbiology Research, vol. 7, no. 27, pp. 3501-3510, 2013.

[48] S. Kapllan, T. Jorida, K. Renata et al., "Incidence of coagulase positive Staphylococcus aureus in raw cow milk produced by cattle farms in Fieri Region in Albania," Life Science Journal, vol. 7, no. 4, pp. 390-394, 2013.

[49] A. Fufa, A. Tekeste, G. Fikru et al., "Staphylococcus: isolation, identification and antimicrobial resistance in dairy cattle farms, municipal abattoir and personnel in and around Asella, Ethiopia," JVST, vol. 7, p. 383, 2016.

[50] B. B. Asiimwe, R. Baldan, A. Trovato, and D. M. Cirillo, "Prevalence and molecular characteristics of Staphylococcus aureus, including methicillin resistant strains, isolated from bulk can milk and raw milk products in pastoral communities of South-West Uganda," BMC Infectious Diseases, vol. 17, p. $422,2017$.

[51] B. Takele, H. Halefom, G. Fikru et al., "Prevalence and antimicrobial resistance profile of Staphylococcus in dairy farms, abattoir and humans in Addis Ababa, Ethiopia," BMC Research Notes, vol. 10, p. 171, 2017.

[52] A. Yodit, D. G. Fanta, M. E. Bedaso et al., "Assessment of Staphylococcus aureus along milk value chain and its public health importance in Sebeta, Central Oromia, Ethiopia," BMC Microbiology, vol. 17, p. 141, 2017. 
[53] J. Mueena, R. Marzia, M. Parvej et al., "Isolation and characterization of Staphylococcus aureus from raw cow milk in Bangladesh," Journal of Advanced Veterinary and Animal Research, vol. 2, no. 1, pp. 49-55, 2015.

[54] S. Sudhanthirakodi, S. S. Chinta, and B. Sukumar, "Prevalence of antibiotic resistant Staphylococcus aureus from raw milk samples collected from the local vendors in the region of Tirupathi, India," Veterinary World, vol. 8, no. 4, pp. 478-481, 2015.

[55] D. Fanta, M. Kohei, T. Akafte, and G. Delia, "Contamination of informally marketed bovine milk with Staphylococcus aureus in urban and peri urban areas of Debre-Zeit, Ethiopia," African Journal of Microbiology Research, vol. 6, no. 1, pp. 008-011, 2013.

[56] M. Ananya and B. M. Pranab, "Detection of staphylococci in raw milk and milk products and evaluation of their antibiotic sensitivity: a report from Southern Assam, India," IOSR Journal of Environmental Science, Toxicology and Food Technology, vol. 9, no. 1, pp. 17-22, 2015.

[57] D. Deresse, G. Solomon, and Y. Dawit, "Antibiotic-resistance Staphylococcus aureus isolated from cow's milk in the Hawassa area, South Ethiopia," Annals of Clinical Microbiology and Antimicrobials, vol. 11, no. 26, pp. 1-6, 2012.

[58] G. R. Jolanta, C. Anna, K. Weronika, and O. Jacek, "Occurrence of Staphylococcus aureus on farms with small scale production of raw milk cheeses in Poland," Toxins, vol. 8, no. 3, p. 62, 2016.

[59] R. Pant, S. Nirwal, and N. Rai, "Prevalence of antibiotic resistant bacteria and analysis of microbial quality of raw milk samples collected from different regions of Dehradun," International Journal of PharmTech Research, vol. 5, no. 2, pp. 804-810, 2013.

[60] M. Jibril and N. T. Huruma, "The prevalence of methicillinresistant Staphylococcus aureus (MRSA) isolated from raw bovine milk in the Morogoro Municipality, Tanzania," pp. pp1-66, Sokoine University of Agriculture, Morogoro, Tanzania, 2015, MSc thesis.

[61] S. Purba, M. Debasish, D. Sachinandan, and D. Chanchal, "Staphylococcus aureus in dairy animals and farm workers in a closed herd in Karnal, North India: assessment of prevalence rate and CoA variations," International Journal of Innovative Science Engineering and Technology, vol. 3, no. 4, pp. 1096210972, 2014.

[62] U. H. Abo-Shama, "Prevalence and antimicrobial susceptibility of Staphylococcus aureus isolated from cattle, buffalo, sheep and goat's raws milk in Sohag Governorate, Egypt," Assiut Veterinary Medical Journal, vol. 60, no. 141, pp. 63-72, 2014.

[63] K. B. Anand, P. Agrawal, S. Kumar, and K. Kapila, "Comparison of cefoxitin disc diffusion test, oxacillin screen agar and PCR for mecA gene for detection of MRSA," Indian Journal of Medical Microbiology, vol. 27, pp. 27-29, 2009.

[64] M. Green and A. Bradely, "Clinical forum: Staphylococcus aureus mastitis in cattle," UK VET, vol. 9, pp. 1-9, 2004. 